Mens

Revue d'histoire intellectuelle et culturelle

\title{
Benoît Melançon. Les yeux de Maurice Richard : une histoire culturelle, Montréal, Éditions Fides, 2012, 315 p.
}

\section{Michel Nareau}

Volume 13, numéro 2, printemps 2013

URI : https://id.erudit.org/iderudit/1025989ar

DOI : https://doi.org/10.7202/1025989ar

Aller au sommaire du numéro

Éditeur(s)

Centre de recherche en civilisation canadienne-française

ISSN

1492-8647 (imprimé)

1927-9299 (numérique)

Découvrir la revue

Citer ce compte rendu

Nareau, M. (2013). Compte rendu de [Benoît Melançon. Les yeux de Maurice Richard : une histoire culturelle, Montréal, Éditions Fides, 2012, 315 p.] Mens,

13(2), 119-122. https://doi.org/10.7202/1025989ar d'utilisation que vous pouvez consulter en ligne.

https://apropos.erudit.org/fr/usagers/politique-dutilisation/ 
la colonie laurentienne, elles sont aussi d'une grande complexité. Par exemple, la transition du marché du livre, à Québec, semble s’effectuer en douceur, tandis qu'on ne sait toujours rien des conséquences du changement de pôle de référence ultime, Paris et Londres, dans le développement du fait littéraire à la fin du XVIII ${ }^{\mathrm{e}}$ siècle québécois. Il faut signaler, finalement, l'absence surprenante de références à Charles Berger, premier partenaire financier de Mesplet dans son établissement montréalais. Une zone d'ombre qui tend à cristalliser le tandem emblématique voltairien de Mesplet-Jautard, aux dépens de l'association d'affaire Mesplet-Berger. Autrement dit, l'aspect strictement littéraire de la gazette plutôt que son aspect commercial, comme si les deux réalités étaient autonomes.

- François Melançon Chercheur indépendant

\section{Benoît Melançon. Les yeux de Maurice Richard: une histoire culturelle, Montréal, Éditions Fides, 2012, 315 p.}

Rares sont les essais québécois qui acquièrent une reconnaissance sociale et intellectuelle quasi immédiate. C'est le cas des Yeux de Maurice Richard: une histoire culturelle de Benoît Melançon, paru initialement en 2006, et déjà rendu à sa troisième édition, cette fois dans un format de poche. La fortune de ce texte se perçoit par sa réception enthousiaste, par les prix remportés (prix Maurice-Arès 2006 ; prix Marcel-Couture 2007), par sa traduction vers l'anglais, mais surtout par la multiplication des essais universitaires consacrés à l'examen socioculturel du hockey, enfant pauvre de la réflexion en sciences humaines avant la publication de l'essai et dorénavant manne éditoriale, hélas pas toujours fructueuse.

Cet essai met en évidence de quelle manière Maurice Richard est mythifié à travers des discours, des objets, des images, des chansons qui répondent tous à une volonté d'identification avec l'héroïsme du hockeyeur et à un besoin de compensation où le Rocket devient le modèle de comportements valorisés par la collectivité. Melançon 
n'est pas le premier à affirmer que Richard acquiert du sens parce que la communauté s'est identifiée à ses exploits, à son style, à ses triomphes et qu'elle a investi une axiologie dans son parcours et dans l'Émeute dont il a été l'épicentre. Mais il innove assurément en refusant de participer à ce mythe, en repérant les traces de ce discours et en l'organisant en suites compréhensibles qui permettent au lecteur de saisir autant la malléabilité discursive du mythe que la chronologie de l'exhaussement de Richard au rang de précurseur de la Révolution tranquille.

Le sous-titre de l'ouvrage est significatif; l'auteur procède en effet à une histoire culturelle inspirée des travaux de Roger Chartier. Il met en commun des récits, des articles de journaux, des pièces de théâtre, des photos et des films. Une abondante production artistique, de valeur évidemment variable, est mise à contribution, analysée, répertoriée, contextualisée. Mais à cette production, populaire ou instituée, qui détermine usuellement le champ de la mise en représentation d'une pratique culturelle, Melançon ajoute des objets émanant du circuit économique, de la vente et de la publicité, de même que le discours de commémoration au décès du joueur, où la parole est laissée à la foule anonyme qui témoigne de son attachement au numéro 9. La multiplicité de ces sources est l'intérêt premier de l'essai, le mythe s'abreuvant de tous les côtés. Mais le traitement proposé par Melançon recèle, à mon avis, un intérêt méthodologique encore plus grand, parce que le chercheur ne tente pas simplement d'amalgamer des objets trop souvent distingués, la publicité et le roman par exemple, mais parce qu'il montre comment ces types de discours et de représentations fonctionnent en réseau et différemment, apportent des éclairages singuliers, tout en reconduisant des topos plus généraux quant à l'organisation hégémonique de ces pratiques discursives spécifiques. C'est une chose que d'aborder une lampe à l'effigie de Richard après avoir évoqué un conte de Roch Carrier; c'en est une autre que de manier le contexte qui rend intelligibles ces objets dans les suites assemblées. 
La légitimation d'un nouvel objet d'étude et d'un corpus original s'appuie sur une perspective historique, où des découpages organisent la mise en récit du mythe, à travers des dominantes. Un des apports de l'essai est de cerner les mutations du mythe opérées en fonction du déplacement des enjeux sociaux au Québec. Dans le discours sur Maurice Richard, il y a des périodes de surabondance, d'autres plus calmes, ce qui indique que la réception du joueur varie en fonction des besoins culturels de ceux qui utilisent l'athlète. Melançon signale le glissement qui s'opère entre le joueur fougueux des années 1950, celui qui tient tête aux dirigeants anglophones, et le grand-père modèle des années 1980. Il en va de même entre les deux lectures nationalistes : l'une privilégie, dans les années 1960 et 1970, l'image du précurseur de la Révolution tranquille, en marquant fortement son appartenance sociale et culturelle à la collectivité, l'autre, assez contemporaine, insiste sur sa capacité à réussir à l'étranger, ouvrant la voie au Cirque du Soleil et autres Céline Dion.

S'il y a une trame commune à tous ces Maurice Richard (ses exploits canoniques, ce que Melançon nomme ses douze travaux; sa familiarité avec la culture populaire québécoise; le passage obligé par l'Émeute; l'ambiguïté de l'individu (avec ses contradictions) et qui trouve à se révéler dans son surnom, le Rocket), n'en demeure pas moins une diversité d'interprétations et de formulations. Si la voie historique permet de cerner cette évolution, tout comme la multiplication des supports, il convient de noter qu'une des portes pour cerner cette labilité du discours n'est pas souvent ouverte, celle de la langue. Maintes fois, le Rocket est interprété comme un objet culturel uniquement francophone. L'essai de Paul Daoust, exactement contemporain de celui de Melançon, en apportait la preuve éclatante en 2006. Toutefois, la perspective de ce dernier est plus riche, alors qu'il n'hésite pas à plaider pour un mythe aussi canadien que québécois. Entrelaçant les deux discours sur Richard, l'auteur se distancie du mythe et montre que l'une des dimensions de celui-ci est justement d'établir cette concordance entre le Rocket et le Québec, concordance pourtant elle-même porteuse de contradictions autrement glissées 
sous le tapis et explicitées dans l'essai (pensée politique, ambivalence identitaire, affinités avec des politiciens, langue problématique, etc.).

S’il fallait mettre en évidence un élément moins convaincant de la riche interprétation du discours sur Maurice Richard, ce serait la volonté manifeste de singulariser à tout prix le hockeyeur des autres figures sportives dont le parcours pourrait les apparenter au joueur du Canadien. En cherchant à isoler le mythe Richard des héros et légendes sportives, Melançon peut certes distinguer la portée des attributions identitaires apposées à Richard, mais il le fait en dévaluant une part du caractère récurrent des procédés d'identification, de compensation et de mise en discours qui sont employés pour énoncer le sport. Il suffit de penser à la manière dont le court séjour de Jackie Robinson à Montréal est utilisé au Québec depuis au moins trente ans afin de valoriser l'ouverture à l'autre de la population francophone, pour comprendre que le discours sur l'héroïsme échappe souvent à l'arène sportive pour épouser les enjeux sociaux et discursifs d'une collectivité. Il en va de même de la figure de Jos Montferrand, non abordée par Melançon, et qui me semble correspondre à la définition du mythe qu'il propose, en vertu, entre autres, de sa longévité et du caractère malléable des interprétations de ses exploits.

En montrant la nécessité d'historiciser les discours récents au Québec, en traitant de la culture populaire sans l'opposer à une culture lettrée dont elle serait l'exact opposé, en légitimant l'étude culturelle du sport, en proposant des avancées méthodologiques, en sortant Richard d'une perspective monolithique, Melançon a ouvert de nombreuses voies, ce qui explique la résonance de sa contribution dans le paysage culturel québécois.

- Michel Nareau

Collège militaire royal du Canada 